The following pages constitute the final, accepted and revised manuscript of the article:

Ohlsson, $\mathrm{H}$ and Lindblad, $\mathrm{U}$ and Lithman, $\mathrm{T}$ and Ericsson, $\mathrm{B}$ and Gerdtham, U and Melander, A and Råstam, L and Merlo, J

"Understanding adherence to official guidelines on statin prescribing in primary health care-a multi-level methodological approach"

Eur J Clin Pharmacol. 2005 Nov;61(9):657-65.

Publisher: Springer.

Use of alternative location to go to the published version of the article requires journal subscription.

Alternative location: http://dx.doi.org/10.1007/s00228-005-0975-9 


\title{
Understanding adherence to official guidelines on statin prescribing in primary health care - a multi-level methodological approach
}

Ohlsson $\mathrm{H}^{1,2}$, Lindblad $\mathrm{U}^{2,3}$, Lithman $\mathrm{T}^{1}$, Ericsson $\mathrm{B}^{1}$, Gerdtham $\mathrm{U}_{-} \mathrm{G}^{2}$, Melander $\mathrm{A}^{4}$, Råstam L ${ }^{2}$, Merlo $\mathrm{J}^{2}$

\author{
${ }^{1}$ Drug Utilization Unit, Scania Region, Lund, Sweden \\ ${ }^{2}$ Community Medicine, Department of Medical Science, Malmö University Hospital, Faculty \\ of Medicine, Lund University, Malmö, Sweden \\ ${ }^{3}$ The Skaraborg Institute, Skövde, Sweden \\ ${ }^{4}$ The NEPI Foundation, Malmö University Hospital, Malmö, Sweden
}

This study has been presented as an abstract at the 20th International Conference of Pharmacoepidemiology and Therapeutic Risk Management, Bordeaux, France, in August 2004, the 3rd Nordic Conference in Epidemiology, Kuopio, Finland, in June 2004 and the first Nordic Social Pharmacy and Health Service Research Conference, Uppsala, Sweden, in October 2004.

\section{Corresponding authors:}

Henrik Ohlsson, MSci

Drug Utilization Unit, Scania Region, Lund, Sweden

Regionhuset

Box 1

S-221 00 Lund

Sweden

henrik.ohlsson@skane.se

and

Associate Prof. Juan Merlo, MD, PhD

Community Medicine

Department of Medical Science

Malmö University Hospital

Faculty of Medicine, Lund University

S-205 02 Malmö

Sweden

juan.merlo@med.lu.se

\section{Number of words:}

Manuscript: 3577 words

Abstract: 265 words 


\section{ABSTRACT}

\section{Objective}

The aim was to investigate the role that municipalities and out-patient health care centres (HCCs) have in understanding adherence to official guidelines on statin prescribing. Our hypothesis was that after guideline publication, adherence to recommended statins prescription would increase and variance between HCCs and municipalities would decrease. Since multi-level regression analysis (MLRA) is a relatively new methodology in pharmacoepidemiology, we also aimed to explore the application of MLRA in our investigation.

\section{Methods}

We obtained data from the Swedish Corporation of Pharmacies record of sales regarding all initial prescriptions of statins issued between April and December 2003. We applied multilevel analysis on 34514 individual prescriptions (level 1) nested within $226 \mathrm{HCCs}$ (level 2), which in turn were nested within 33 municipalities (level 3). Temporal trends and gender differences were investigated by random slope analysis. Variance was expressed using median odds ratio (MOR) and interval odds ratio (IOR).

\section{Results}

Health care centres appeared to be more relevant than municipalities for understanding physicians' propensity to prescribe a recommended statin $\left(\mathrm{MOR}_{\mathrm{HCC}}=1.96\right.$ and $\mathrm{MOR}_{\text {Municipality }}$ $=1.41$ ). Overall prevalence of adherence was very low (about 20\%). After publication of the guidelines, prescription of recommended statins increased and variance between HCCs decreased but only during the first 4 months of the observation period.

\section{Conclusion}

The publication of official guidelines in the county of Scania exerted a positive influence on statin prescription but at the end of the observation period adherence was still low and practice variation high. These facts may reflect inefficient therapeutic traditions, and suggest that more intensive interventions may be necessary to promote rational statin prescription. 


\section{INTRODUCTION}

The importance of appropriate prescribing for the well-being of the patient and for efficient use of limited health budgets cannot be exaggerated. Since 1997 every Swedish county has had a drug committee charged with promoting safe and cost-efficient drug use based on evidence-based medicine (1). The committees aim to recommend medications appropriate to clinical needs, in doses that meet their patients' individual requirements, for an adequate period of time and at the lowest costs to the community (2). The recommendations respect the patient's choices and strive to maximize effectiveness while minimizing risks and costs (3). However, despite the existence of formal committees and guidelines on appropriate prescription, it is still not known to what extent these criteria are being followed and which factors may condition adherence to guidelines (4).

This study aimed to investigate variance between different municipalities and out-patient health care centres (HCCs) regarding adherence to guidelines on statin prescribing issued by the county council of Scania, Sweden, in March 2003. We wanted to investigate prescribing behaviour, and statins are an ideal medication group for this purpose since prescription of recommended statins is indicated for certain patients but not for others and since all statins have a similar efficacy (dependent on the particular dose used). We also analysed prescriptions rather than dispensations by the pharmacies because dispensations are conditioned by the pharmacist (e.g. with dispensation of generic drugs). Our hypothesis was that adherence to guidelines would result in increased use of recommended statins and decreased variance between HCCs and municipalities along the observation period.

Moreover, since multi-level regression analysis (MLRA) is a relatively new methodology in Pharmacoepidemiology, we also aimed to explore the application of this methodology for investigating practice variation. Multi-level regression analysis allows us to understand not only which patient, HCC and municipality characteristics are associated with adherence to 
recommended statins, but also, the relative role of these different levels for successful adherence to prescription guidelines $(5,6)$.

\section{MATERIALS AND METHODS}

\section{The register of pharmacological agents}

Using the Swedish Corporation of Pharmacies record of sales we selected all 34514 prescriptions (16 400 for women and 18114 for men) of statins issued between April and December 2003 at 226 HCCs in the 33 municipalities of Scania. Statins were defined according to the Anatomical Therapeutical Chemical (ATC) classification system code C10AA. The current prescription guidelines in the county were published in March 2003 and we started our evaluation in April in order to allow a running-in period and exclude the initial short-term variation.

In the register each prescription, regardless of number of drugs, is given a unique serial number. Among other data the register records information about the brand name and ATC code for both prescribed and dispensed drugs as well as stating whether the prescription is a repeat prescription or not. Moreover, the register records the age and gender of the patient as well as the HCC where the prescription was issued. Prescriptions issued at hospitals, at unidentified places, at places outside Scania and by a prescriber with no agreement with the county council are not recorded in the database.

Though a prescription is valid for 1 year, the reimbursement system accepts a maximum of 3 months' supply per dispensation. Since we evaluated adherence to the prescription guidelines issued in March 2003 we investigated only those prescriptions that were issued after this date. Since dispensations are for 3 months, but prescriptions for 1 year, we selected initial prescriptions only in order to reduce the risk of analysing the same prescription twice. 
In practical words, a patient may get a prescription of statin that covers a whole year.

However, the rules say that you cannot get the whole year supply in one occasion, but every three moths. For this reason we only accounted for the first dispensation within the study period.

\section{Variables}

At the individual level the outcome variable was prescription (yes v. no) of Simvastatin GEA ${ }^{\circledR}$ or Pravachol ${ }^{\circledR}$, the two recommended brands in the county during the period of our analysis. By law the Swedish Society of Pharmacies dispenses the cheapest alternative of equivalent drugs, if patient and doctor agree. Therefore, since the aim of our study was to investigate determinants of prescription rather than of dispensation, we performed our main analysis on prescribed drugs.

Age was centred on the mean age of 66 years. We created dummy variables to define sex, and every one of the five health care districts in the county (North-West, North-East, South-West, South-East and Central) as well as for the administrative status (private v. public) of the HCC. Private physicians are less restricted by the public health care administration, which could be expressed in a lower adherence with county guidelines

We considered time (in months) as a continuous variable (April $=0$, May $=1, \ldots$ December $=8$ ) that was modelled as a quadratic function. At the municipality level we obtained the variable physician density, defined as number of physicians per 10000 inhabitants in the 33 municipalities in Skåne.

\section{Statistical analysis}

\section{Multi-level logistic regression models}

Because of the hierarchical structure of the data, with patients (first level) nested within HCCs (second level) which, in turn, were nested within municipalities (third level), we analysed the probability of prescribing a recommended statin by MLRA $(7,8)$. 
We applied three consecutive models. The first model (model A) only included the time variable. In the second model (model B) we included age and sex. In the third model (Model C) we added the HCC-level variable private v. public HCC and the municipality-level variables physician density and health care district.

To study associations we calculated odds ratios (OR) and their $95 \%$ confidence interval $(95 \% \mathrm{CI})$ from the regression coefficients and their standard error (SE) in the fixed-effects part of the multi-level analysis.

\section{Ranking of health care centres}

We compared the probability of prescribing a recommended statin in every HCC with the mean probability in the whole county and ranked the HCCs according to this information. For doing this comparison we obtained the posterior means (also called "shrunken residuals") from the multi-level regression. These residuals corresponded with the OR (logarithmic scale), with the whole county as reference (9-11).

Variance, variance function and proportional change in variance

In the random-effects part of the multi-level analysis we obtained the variance (SE) at the HCC and municipality levels. We calculated the proportional change in variance (PCV) between two consecutive models as follows:

$$
\mathrm{PCV}=\left(\mathrm{V}_{0}-\mathrm{V}_{1}\right) / \mathrm{V}_{0}
$$

where $\mathrm{V}_{0}$ is the variance in the initial model and $\mathrm{V}_{1}$ is the variance in the model with more terms.

We allowed the regression coefficients of the variables time and sex to be random at the HCC level (i.e. random slope analysis). In this way we were able to investigate whether trends of gender-specific prescribing of recommended statins differed between different HCCs. In presence of random slopes the HCC variance becomes a function of the individual variables. We used standard applications available in the MLwiN software (12) for 
the calculation of the variance function. Details of the formulas and an extended explanation are found elsewhere $(13,14)$.

Examining local therapeutic traditions by multi-level regression analysis

Since prescription of recommended statins depends solely on the arbitrary decision of the prescriber, it appears theoretically plausible to expect no significant variance between HCCs and municipalities in the prescription of recommended statins. However, if such variance existed, the tendency of prescribing a recommended statin may be more similar among prescribers within the same HCC and the same municipality than among prescribers from different HCCs and municipalities. This similarity (i.e. residual correlation, in statistical terms) would express itself as a clustering of prescriptions of recommended statins within HCCs and municipalities $(10,15,16)$. That is, a part of the individual propensity of prescribing a recommended statin would be at the HCC or municipality level. Our rationale was that this phenomenon is an expression of local therapeutic traditions and can be investigated by measures of variance and clustering in MLRA (see below).

We expected that possible local therapeutic traditions (i.e. unexplained practice variation) would decrease after the official guidelines were published in March 2003 and in this study we aimed to describe this variance.

The median odds ratio

Direct epidemiological interpretation of HCC and municipality variance in the logistic regression is difficult $(7,17)$. One suitable alternative is calculating the median odds ratio (MOR), as proposed by Larsen and co-authors $(8,18)$. The MOR translates the variance in the widely used OR scale, which has a consistent and intuitive interpretation. The MOR can be directly compared with the ORs of individual or area variables. In very simple terms the MOR could be interpreted as the increased (median) probability of being prescribed a recommend 
statin if a patient was to change HCC (or municipality). The MOR depends directly on the HCC-level variance and can be computed with the following formula:

$$
\mathrm{MOR}=\exp \left[\sqrt{ }\left(2 \times \mathrm{V}_{\mathrm{HCC}}\right) \times 0.6745\right] \approx \exp \left(0.95 \sqrt{ } \mathrm{V}_{\mathrm{HCC}}\right)
$$

where $\mathrm{V}_{\mathrm{H}}$ is the $\mathrm{HCC}$-level variance, and 0.6745 is the 75 th percentile of the cumulative distribution function of the normal distribution with mean 0 and variance 1 .

If the MOR was equal to 1, there would be no differences between HCCs in the probability of prescribing a recommended statin. If there were important HCC-level differences, the MOR would be large.

The accuracy of the variance estimates was evaluated by their SE. We applied an approximate normal test for the calculation of $p$-values. A $p$-value $>0.05$ was considered nonsignificant (NS).

\section{The $80 \%$ interval odds ratio}

Contrary to individual-level variables in multi-level models, area variables only take one value in each area and, consequently, it is necessary to compare individuals from different HCCs or municipalities to quantify area-level associations $(19,20)$. Therefore we need to incorporate the $\mathrm{HCC} /$ municipality variance in the presentation of area-level associations. For this purpose, we applied the $80 \%$ interval odds ratio (IOR-80) as described in detail elsewhere $(8,18,20)$. The lower and upper bounds of the IOR can be computed with the following equations:

$$
\begin{aligned}
& \mathrm{IOR}_{\text {lower }}=\exp \left[\beta+\sqrt{ }\left(2 \times \mathrm{V}_{\mathrm{H}}\right) \times(-1.2816)\right] \approx \exp \left(\beta-1.81 \sqrt{ } \mathrm{V}_{\mathrm{H}}\right) \\
& \mathrm{IOR}_{\text {upper }}=\exp \left[\beta+\sqrt{ }\left(2 \times \mathrm{V}_{\mathrm{H}}\right) \times(1.2816)\right] \approx \exp \left(\beta+1.81 \sqrt{ } \mathrm{V}_{\mathrm{H}}\right),
\end{aligned}
$$

where $\beta$ is the regression coefficient for the hospital-level variable, $V_{H}$ is the hospital-level variance, and the values -1.2816 and +1.2816 are the 10 th and 90th percentiles of the normal distribution, with mean 0 and variance 1 (see (8) (18) (20) for further explanation). 
It should be noted that the IOR-80 is not a common confidence interval. The interval is narrow if the residual variation between different HCCs is small, and wide if this variation is large. If the interval contains the value 1 , this indicates that the effect of the higher-level characteristic under scrutiny is not that important when compared with the remaining residual higher-level heterogeneity. The IOR therefore complements the information provided by the normal OR.

The analyses were performed using the MLwiN 1.2 software developed by Goldstein research group $(9,17)$. Parameters were estimated by restricted iterative generalized least square (RIGLS) method (12).

\section{RESULTS}

Table 1 indicates that the prevalence of adherence with guidelines for prescription of statins was overall $20 \%$ and this prevalence was the same for both men and women. The number of private HCCs was similar to the number of public HCCs and physician density was lower in the North-West and North-East health care districts than in the other three health care districts.

In Table 2, model A shows that factors related to the $\mathrm{HCC}$ and municipality level together played a relevant role in understating individual prescription of recommended statins $\left(\mathrm{MOR}_{\text {Municipality-HCC }}=2.13\right)$. However, it appears that HCCs are more relevant than are municipalities in this context $\left(\mathrm{MOR}_{\mathrm{HCC}}=1.96\right.$ and $\left.\mathrm{MOR}_{\text {Municipality }}=1.41\right)$.

The ranking of the HCCs and municipalities regarding their prevalence of use of recommended statins relative to the overall prevalence in the county at the beginning of the study period (i.e. intercept residuals) is presented in Figure 1 both before (model A) and after (model C) making adjustments. The differences between the municipalities disappeared after 
adjustment, but the picture for HCCs is different. Many HCCs changed position in the ranking but the dispersion around the mean was only slightly reduced after adjustments in model C. The PCV indicates that $75 \%$ of the differences between municipalities were explained by the individual and contextual characteristics included in model C. However, this percentage was only $3 \%$ in relation to variance between HCCs.

Table 2 also shows that there was a significant temporal trend in prescription of recommended statins. Overall, the trends follow a quadratic function that is illustrated in Figure 2, with a steeper slope at the beginning of the period that levelled off and even decreased at the end of the study period. This Figure also shows that many specific HCC temporal trends differed from the overall trend in the county.

The probability of being prescribed a recommended statin increased for every year of age though by a very low degree. Men had a lower probability than women of being prescribed a recommended statin but — as in the case of the temporal trend described above — this association differed in different HCCs. Because of the existence of significant slope variance in the association between prescription of recommended statins and both time and sex, the HCC variance became a function of these variables. This phenomenon is illustrated in Figure 3 where we also show the effect of the adjustments performed in models B and C.

Regarding municipality and HCC-level variables, Table 2 shows that the probability of prescribing recommended statins was similar in private and in public HCCs. The IOR-80 was wide, confirming the low relevance of this variable for understanding adherence to guidelines on statin prescription.

Compared with the North-West, the South-East health care district exhibited a higher adherence to the county's guidelines on statin prescription. However, in this case the IOR-80 was also very wide, indicating the low importance of this variable for understanding differences in adherence to guidelines between HCCs. 
Physician density — a municipality characteristic — appeared to play a role in improving adherence, but this association was U-shaped, with the lowest probability in the second tertile group. The IOR-80 was relatively wide but this actually suggests that this variable may have some relevance for the implementation of prescription guidelines.

\section{DISCUSSION}

We present a relatively new analytical approach for drug utilization studies in Pharmacoepidemiology. Multi-level regression analysis reveals the role of different levels for understanding drug prescription and utilization $(5,6)$. Hierarchical structures (e.g. patients nested within physician in different HCCs nested within counties in different countries) are common in Pharmacoepidemiology and MLRA allows an appropriate analysis of hierarchical structures for both statistical and epidemiological purposes $(5,21)$. In the present paper moreover of providing some extended methodological description of MLRA, we propose a model of analysis for investigating practice variation in general and adherence to statin prescription guidelines in particular.

We used the month of April 2003 as starting point in our evaluation since guidelines were published in of the middle of March. In April each HCC and municipality has a specific level of prescription, and our hypothesis was that successful adherence with guidelines would convey increasing prevalence of use of recommended statins and decreasing variance between HCC and municipalities along the observation period. Therefore, including a period of time (e.g., January February and March) before the guidelines would not change our result regarding trends in prevalence and variation during the observation period. Moreover, the investigation of the association between physician density and health care districts and adherence with guidelines can only be done after these guidelines were actually published in the middle of March. 
There are few therapeutic reasons for choosing a more expensive drug brand among several brands of similar efficacy. Nevertheless, this practice was fairly common in the county, and the MLRA revealed substantial practice variation that may reflect local therapeutic traditions which hindered prescription of recommended statins.

Adherence to guidelines seemed to a considerable degree to be conditioned by contextual factors at the $\mathrm{HCC}$ and municipality levels. Physicians from the same HCCs and from the same municipalities showed a similar propensity to prescribe recommended statins. In other words, HCC and municipality levels appear to bear a significant part of the prescriber's inclination to issue a recommended statin. This relative "responsibility" (6) for successful adherence to prescription guidelines was higher for the HCC than for the municipality level.

These results, illustrated in Figure 3, suggest that in some way the publication of the official prescription guidelines reduced the initial practice variation, from $\mathrm{MOR} \approx 2$ in April to $\mathrm{MOR} \approx 1.5$ in September 2003 . Thereafter practice variation increased slightly but never reached the heterogeneity observed at the beginning of the observation period.

It should be noted that some HCCs that showed relatively high adherence in April showed a clear decreasing trend along the study period. The reasons for this behaviour need be investigated in particular. Excluding the outlier with the highest adherence in April from the analysis decreased the HCC variance from 0.500 to 0.420 and increased the municipality variance from 0.132 to 0.158 but did not have a major effect on slope variance. In this study we did not have access to information at the physician level. A part of the HCC variation found could therefore in fact be physician variation $(6,22,23)$, an aspect we observed in the Skaraborg Primary Health Care Database containing information from general practitioners' medical records (24). 
Practice variation is a common phenomenon which need not necessarily be inappropriate but rather, which may reflect equivalent therapeutic traditions confronting a similar health problem (25-28). However, when the same pharmacological agent is available in different brands at very different prices and the prescriber chooses the expensive brand, it is relevant to investigate determinants for these prescription disparities in order to launch interventions promoting appropriate prescription (29). In this context, statins are an illustrative group of pharmacological agents since they have concrete indications (30). They are the first-hand choice for treatment of hyperlipidaemia in adults with a high risk of developing heart disease. Statins have shown to be effective in primary and, more specifically, secondary prevention of coronary heart disease and ischaemic stroke $(31,32)$. Since all statins have the same indication and only marginal differences in efficacy there are no solid reasons why expensive brands should be prescribed in general and for some patients rather than others in particular.

The process of prescription includes a number of phases (identification of the health problem, decision to prescribe, choice of medication, decision to cease using specific therapy) and could be influenced at different levels (e.g. at the patient, prescriber, HCC or health care district level). However, very few studies have aimed to understand the relative importance of these different levels $(6,22,23)$. Therefore, the present investigation provides valuable and original information that could be of relevance for planning and evaluating interventions aimed to promote efficient and evidence-based prescription.

In this study we were interested in investigating prescribing behaviour, and statins are an ideal medication group for this analysis. Prescription of recommended statins is not specifically indicated for certain patients to the exclusion of others. There is therefore no rationale for considering patient characteristics as confounder factors. Rather, the interest in these variables resides in understanding reasons for low adherence to prescribing guidelines. 
In the present investigation we only considered basic individual variables such as age and gender; however, a study of determinants of adherence to guidelines may require a qualitative research methodology (33).

We found a rather low prevalence of adherence with recommended statins. The main reason for the low use of recommended statins is that the guidelines were very strict including only Pravachol and Simvastatin GE.

It is known that some non recommended statins like rosuvastatin have been the subject of safety concerns (34-36). This fact may promote adherence with recommended statins over and above the guidelines. However, this external influence should have affected all the health care centres and municipalities and has therefore less relation with variance in adherence with guidelines.

Our empirical analysis found that - even if in a small degree - women had a higher probability than men of being prescribed cheaper recommended statins. The reasons for this behaviour seem not rational but we do think the results raise an interesting question. Our epidemiological study suggests that it may be interesting to perform further investigation like e.g., a qualitative analysis in order to obtain more information on the reasons for this prescribing behaviour.

We found that municipality physician density influenced adherence to prescription guidelines. In other words, adherence was lower when the physician density was in the middle tertile group. As far as we know, this subject has been rarely investigated in previous studies and deserves more attention.

Multi-level regression analysis has been successfully employed in a number of previous studies in the field $(6,22,23,37)$, and appears to be a useful epidemiological tool for investigating and quantifying medical practice variation. Consequently, MLRA may prove to be a useful tool for evaluating and planning interventions. 
In conclusion, adherence increased and the variation decreased along the study period, which suggests that in some way the publication of the official prescription guidelines in the county had a positive influence on statin prescribing. However, at the end of the observation period adherence was still low and practice variation high. These facts may reflect inefficient therapeutic traditions, and suggest that more intensive interventions may be necessary to promote adherence to prescription guidelines (38). 


\section{Acknowledgements}

This study was supported by grants from the Scania Region's Health Care Research Funds, the Swedish Council for Working Life and Social Research (FAS) (Juan Merlo; Dnr 20030580), and the Swedish Research Council (VR) (Juan Merlo; Dnr 2004-6155) 


\section{REFERENCES}

1. Sjöqvist F, Dahl M-L, Gustafsson L, Hensjö L-O. Drug therapeutics committees: a Swedish experience. WHO Drug Information. 2002;16:207-13.

$2 . \quad$ WHO Conference of Experts on the Rational Use of Drugs, Nairobi. Geneva, Switzerland: WHO; 1987.

3. Barber N. What constitutes good prescribing? Bmj 1995;310(6984):923-5.

4. Läkemedelsförsäljningen i Sverige - analys och prognos, Maj 2004 (Drug sales in Sweden - analysis and prognosis, May 2004) [in Swedish]. Stockholm, Sweden: Socialstyrelsen; 2004.

5. Merlo J. Multilevel analytical approaches in social epidemiology: measures of health variation compared with traditional measures of association. J Epidemiol Community Health 2003;57(8):550-2.

6. Lopez-Valcarcel B, Ortun-Rubio V, Cabez-Mora A, Lopez-Cabañas A, DiazBerenger J, Alamo-Santana F. Evaluation del uso apropiado de medicamentos en atencion primaria. Como se puede mejorar? (Evaluation of the appropriate use of medication in primary care - how do we improve it?) [in Spanish]. Aten Primaria 2002;30:467-471.

7. $\quad$ Rasbash J, Steele F, Browne W. Logistic models for binary and binomial responses. In: A User's Guide to MLwiN. Version 2.0. Documentation Version 2.1e. London, UK: Centre for Multilevel Modelling, Institute of Education, University of London; 2003.

8. Larsen K, Merlo J. Appropriate assessment of neighborhood effects on individual health: integrating random and fixed effects in multilevel logistic regression. Am J Epidemiol 2005;161(1):81-8.

9. Goldstein H. Multilevel Statistical Models. 3rd ed. London, UK: Hodder

Arnold; 2003.

10. Snijders T, Bokser R. Multilevel analysis: an introduction to basic and advanced multilevel modeling. Thousand Oaks, California: Sage Publications; 1999.

11. Burton P, Gurrin L, Sly P. Extending the simple linear regression model to account for correlated responses: an introduction to generalized estimating equations and multi-level mixed modelling. Stat Med 1998;17(11):1261-91.

12. Rasbash J, Steele F, Browne W. A User's Guide to MLwiN, Version 2.0. Documentation Version 2.1e. London, UK: Centre for Multilevel Modelling, Institute of Education, University of London; 2003.

13. Rasbash J, Browne W, Goldstein H, Yang M, Plewis I, Healy M, et al.

Modelling the variance as a function of explanatory variables. In: A User's Guide to MLwiN. Version 2.0. Documentation Version 2.1e. London, UK: Institute of Education, University of London; 2003.

14. Merlo J, Yang M, Chaix B, Lynch J. A brief conceptual tutorial of multilevel analysis in social epidemiology - investigating contextual phenomena in different groups of individuals. J Epidemiol Commun Health 2005; In press.

15. Merlo J, Chaix B, Yang M, Lynch J, Råstam L. A brief conceptual tutorial of multilevel analysis in social epidemiology -linking the statistical concept of clustering to the idea of contextual phenomenon. J Epidemiol Commun Health 2005;59:443-449.

16. Merlo J, Chaix B, Yang M, Lynch J, Råstam L. A brief conceptual tutorial of multilevel analysis in social epidemiology - Interpreting neighbourhood differences and the effect of neighbourhood characteristics on individual health. J Epidemiol Community Health 2005; In press.

17. Goldstein H, Browne W, Rasbash J. Partitioning variation in generalised linear multilevel models. Understanding Statistics 2002;1:223-232. 
18.

Larsen K, Petersen JH, Budtz-Jorgensen E, Endahl L. Interpreting parameters in the logistic regression model with random effects. Biometrics 2000;56(3):909-14.

19. Zeger SL, Liang KY, Albert PS. Models for longitudinal data: a generalized estimating equation approach. Biometrics 1988;44(4):1049-60.

20. Merlo J, Chaix B, Ohlsson H, Beckman A, Johnell K, Hjerpe P, et al. A brief con-ceptual tutorial of multilevel analysis in social epidemiology - using measures of clustering in mul-tilevel logistic regression to investigate contextual phenomena. J Epidemiol Community Health 2005; In press.

21. McMahon AD. Approaches to combat with confounding by indication in observational studies of intended drug effects. Pharmacoepidemiol Drug Saf 2003;12(7):5518.

22. Davis P, Gribben B. Rational prescribing and interpractitioner variation. A multilevel approach. Int J Technol Assess Health Care 1995;11(3):428-42.

23. Davis P, Gribben B, Lay-Yee R, Scott A. How much variation in clinical activity is there between general practitioners? A multi-level analysis of decision-making in primary care. J Health Serv Res Policy 2002;7(4):202-8.

24. Hjerpe P, Fornwall S, Merlo J. Therapeutic traditions and compliance with local therapeutic guidelines on lipid lowering drugs - a multilevel analysis in the Skaraborg Primary Healthcare Database (SPHD). In: International society for pharmacoepidemiology; 2004; Bordeaux; 2004.

25. Smits HL. Medical practice variations revisited. Health Aff (Millwood) 1986;5(3):91-6.

26. Davis P, Gribben B, Scott A, Lay-Yee R. The "supply hypothesis" and medical practice variation in primary care: testing economic and clinical models of inter-practitioner variation. Soc Sci Med 2000;50(3):407-18.

27. Wennberg JE, Barnes BA, Zubkoff M. Professional uncertainty and the problem of supplier-induced demand. Soc Sci Med 1982;16(7):811-24.

28. Flood AB, Wennberg JE, Nease RF, Jr., Fowler FJ, Jr., Ding J, Hynes LM. The importance of patient preference in the decision to screen for prostate cancer. Prostate Patient Outcomes Research Team. J Gen Intern Med 1996;11(6):342-9.

29. Zara C, Torralba M, Sotoca JM, Prat A, Faixedas MT, Gilabert A. The impact of new drug introduction on drug expenditure in primary health care in Catalunya, Spain. Ann Pharmacother 2005;39(1):177-82.

30. Behandling med lipidsänkande läkemedel vid prevention av hjärt-

kärlsjukdomar. (Treatment with lipid-lowering drugs for prevention of heart diseases) [in Swedish]. Information från Läkemedelsverket 2003;14(ISSN 1101-7104):4.

31. LaRosa JC, He J, Vupputuri S. Effect of statins on risk of coronary disease: a meta-analysis of randomized controlled trials. Jama 1999;282(24):2340-6.

32. Vrecer M, Turk S, Drinovec J, Mrhar A. Use of statins in primary and secondary prevention of coronary heart disease and ischemic stroke. Meta-analysis of randomized trials. Int J Clin Pharmacol Ther 2003;41(12):567-77.

33. Jaye $\mathrm{C}$, Tilyard M. A qualitative comparative investigation of variation in general practitioners' prescribing patterns. Br J Gen Pract 2002;52(478):381-6.

34. Ohlsson O, Kjellström T. Landsomfattande konsensus för behandling av höga blodfetter (För landets läkemedelskommittéordförande LOK). Lund, Sweden; 2003 1/10 2003.

35. The statin wars: why AstraZeneca must retreat. Lancet 2003;362(9393):1341.

36. Läkemedelsverket. Produktresumén revideras för Crestor 2004-06-09. 
37.

Merlo J, Liedholm H, Lindblad U, Bjorck-Linne A, Falt J, Lindberg G, et al. Prescriptions with potential drug interactions dispensed at Swedish pharmacies in January 1999: cross sectional study. Bmj 2001;323(7310):427-8.

38. Hakansson A, Andersson H, Cars H, Melander A. Prescribing, prescription costs and adherence to formulary committee recommendations: long-term differences between physicians in public and private care. Eur J Clin Pharmacol 2001;57(1):65-70. 


\section{Legend to the Figures}

\section{Figure 1}

Differences in adherence to guidelines on statin prescribing among municipalities (top) and health care centres (HCCs) (bottom) before (filled circles) and after (open circles) adjustments for age, gender, administrative status of the HCC (private v. public), and physician density in the municipality and health care district.

\section{Figure 2}

Temporal trends in adherence to guidelines on statin prescription in the county of Scania (thick black line) and in the different health care centres (HCCs).

\section{Figure 3}

Median odds ratio (MOR) expressing differences in adherence to guidelines on statin prescribing between the different health care centres (HCCs) in Scania. Values for men and for women have been adjusted for temporal trends (model A), age and sex (model B) and characteristics of the HCCs and of the municipalities (model C). 
Table 1. Characteristics of the 34514 prescriptions of statins, issued to 16400 women and 18114 men who visited 226 different health care centres (HCCs) in the 33 municipalities of Scania, Sweden. Unless otherwise indicated, values are given in percentages

Whole Skåne North-West North-East Central South-West South-East

\begin{tabular}{|c|c|c|c|c|c|c|}
\hline $\begin{array}{l}\text { Number of statin } \\
\text { prescriptions }\end{array}$ & 34514 & 11318 & 6264 & 6455 & 9149 & 1328 \\
\hline Men $(\%)$ & 52 & 52 & 54 & 54 & 51 & 53 \\
\hline Mean age (years) & 66 & 66 & 67 & 66 & 66 & 67 \\
\hline Number of municipalities & 33 & 8 & 6 & 10 & 4 & 5 \\
\hline Number of HCC & 226 & 72 & 43 & 37 & 52 & 22 \\
\hline Number of private $\mathrm{HCC}$ & 121 & 46 & 19 & 13 & 26 & 17 \\
\hline Physician density* & & 27 & 23 & 43 & 45 & 40 \\
\hline \multicolumn{7}{|l|}{ Recommended statins } \\
\hline Whole time period & 20 & 18 & 18 & 23 & 20 & 28 \\
\hline 0 (April 2003) & 15 & 14 & 13 & 19 & 15 & 16 \\
\hline 1 (May 2003) & 16 & 12 & 12 & 23 & 16 & 23 \\
\hline 2 (June 2003) & 19 & 17 & 16 & 25 & 17 & 34 \\
\hline 3 (July 2003) & 19 & 18 & 20 & 24 & 14 & 20 \\
\hline 4 (Aug 2003) & 21 & 21 & 19 & 26 & 20 & 33 \\
\hline 5 (Sept 2003) & 22 & 22 & 19 & 27 & 21 & 22 \\
\hline $6($ Oct 2003$)$ & 24 & 23 & 22 & 24 & 25 & 31 \\
\hline 7 (Nov 2003) & 20 & 19 & 17 & 21 & 22 & 28 \\
\hline $8($ Dec 2003$)$ & 22 & 18 & 21 & 23 & 26 & 33 \\
\hline
\end{tabular}

* Number of physicians per 10000 inhabitants 


\begin{tabular}{|c|c|c|c|c|}
\hline & Model A & Model B & Model C & \\
\hline Fixed effects & & OR $(95 \%$ CI $)$ & OR $(95 \%$ CI $)$ & \\
\hline Time & $1.25(1.20-1.33)$ & $1.25(1.20-1.33)$ & $1.25(1.20-1.31)$ & \\
\hline Time $^{\wedge} 2$ & $0.98(0.98-0.99)$ & $0.98(0.98-0.99)$ & $0.98(0.98-0.99)$ & \\
\hline Sex & & $0.88(0.82-0.95)$ & $0.89(0.82-0.95)$ & \\
\hline Age & & $1.00(1.00-1.00)$ & $1.00(1.00-1.00)$ & \\
\hline Public v. private $\mathrm{HCC}$ & - & - & $1.01(0.86-1.18)$ & \\
\hline IOR- $80^{*}$ & & & $0.28-3.63$ & \\
\hline \multicolumn{5}{|l|}{ Physician density (rate) } \\
\hline 1st tertile & & & $2.66(1.16-6.06)$ & \\
\hline IOR-80† & & & $0.74-9.53$ & \\
\hline 2nd tertile & & & Reference & \\
\hline 3rd tertile & & & $2.36(1.34-4.16)$ & \\
\hline IOR- $80 \dagger$ & & & $0.66-8.47$ & \\
\hline North-West & - & - & Reference & \\
\hline North-East & - & - & $1.13(0.77-1.68)$ & \\
\hline IOR-80† & - & - & $0.31-4.07$ & \\
\hline South-West & - & - & $1.01(0.60-1.70)$ & \\
\hline IOR- $80 \dagger$ & - & - & $0.28-3.64$ & \\
\hline South-East & - & - & $1.56(1.01-2.41)$ & \\
\hline IOR- $80 \dagger$ & - & - & $0.44-5.61$ & \\
\hline Central & - & - & $1.29(0.83-1.99)$ & \\
\hline IOR- $80 \dagger$ & - & - & $0.36-4.62$ & \\
\hline Random effects & Variance (SE) & Variance (SE) & Variance (SE) & PCV \\
\hline Municipality (intercept) & $0.132(0.51)$ & $0.119(0.048)$ & $0.033(0.022)^{\mathrm{NS}}$ & $75 \%$ \\
\hline MOR $_{\text {Municipality }}$ & 1.41 & 1.39 & 1.18 & \\
\hline HCC (intercept) & $0.500(0.084)$ & $0.495(0.086)$ & $0.484(0.084)$ & $3 \%$ \\
\hline $\mathrm{MOR}_{\mathrm{HCC}}$ & 1.96 & 1.96 & 1.94 & \\
\hline $\mathrm{HCC}$ and municipality (intercept) & 0.632 & 0.615 & 0.517 & $18 \%$ \\
\hline $\mathrm{MOR}_{\text {Municipality-HCC }}$ & 2.13 & 2.11 & 1.99 & \\
\hline Time (slope) & $0.011(0.002)$ & $0.011(0.002)$ & $0.011(0.002)$ & \\
\hline Sex (slope) & - & $0.067(0.022)$ & $0.067(0.022)$ & \\
\hline Patient & $0.994(0.008)$ & $0.989(0.008)$ & $0.989(0.008)$ & \\
\hline
\end{tabular}

$\mathrm{HCC}=$ health care centre. IOR- $80=80 \%$ interval odds ratio. $\mathrm{MOR}=$ median odds ratio. $\mathrm{OR}=$ odds ratio.

$95 \% \mathrm{CI}=95 \%$ confidence interval. $\mathrm{SE}=$ standard error. $\mathrm{NS}=$ non-significant .

$\mathrm{PCV}=$ proportional change in variance $(\mathrm{PCV})$ in model $\mathrm{C}$ using model $\mathrm{A}$ as reference.

*When moving to any private HCC. $†$ When moving to any HCC in any municipality within the North-West health care district. 

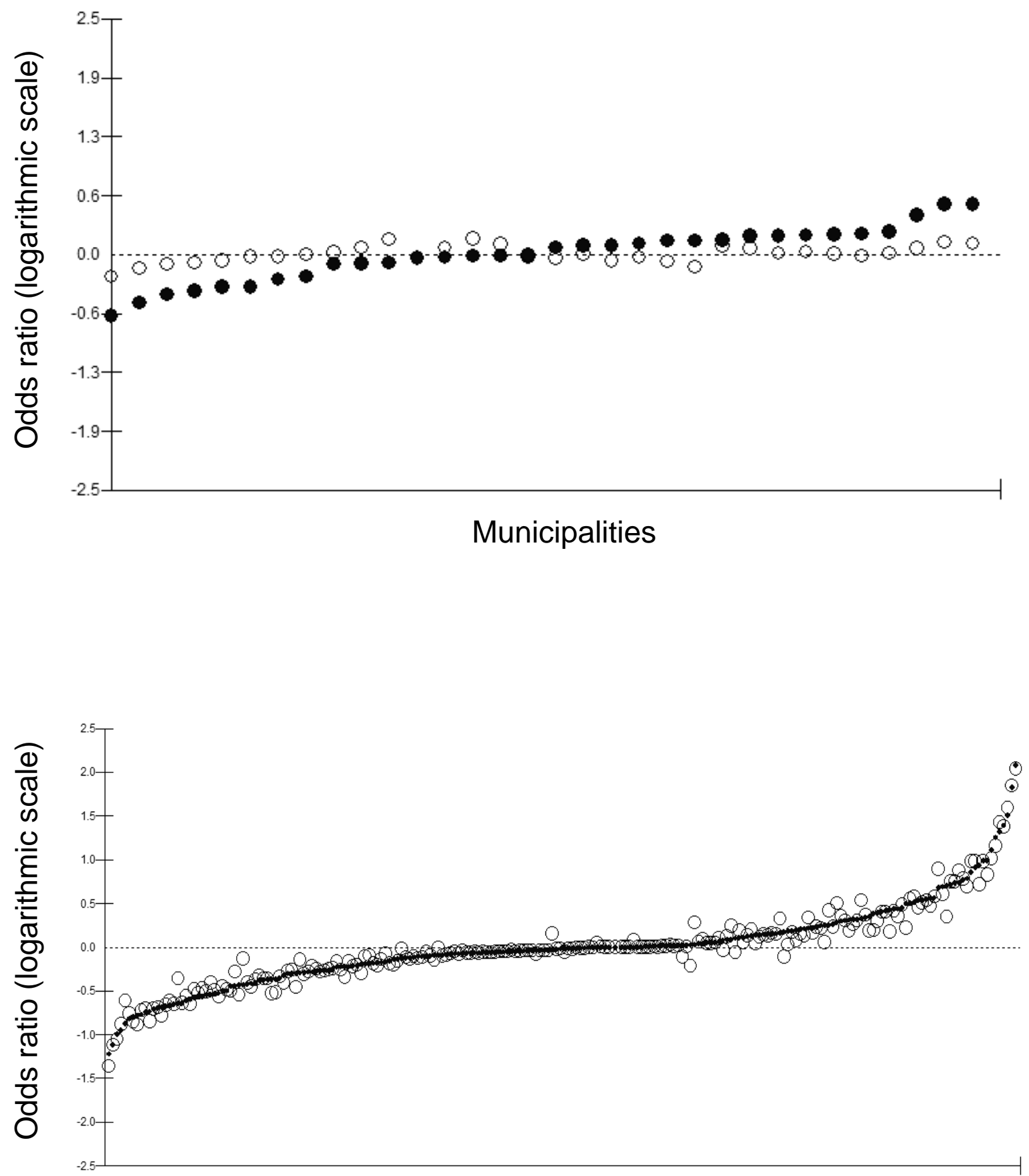

Primary health care centres

Figure 1 


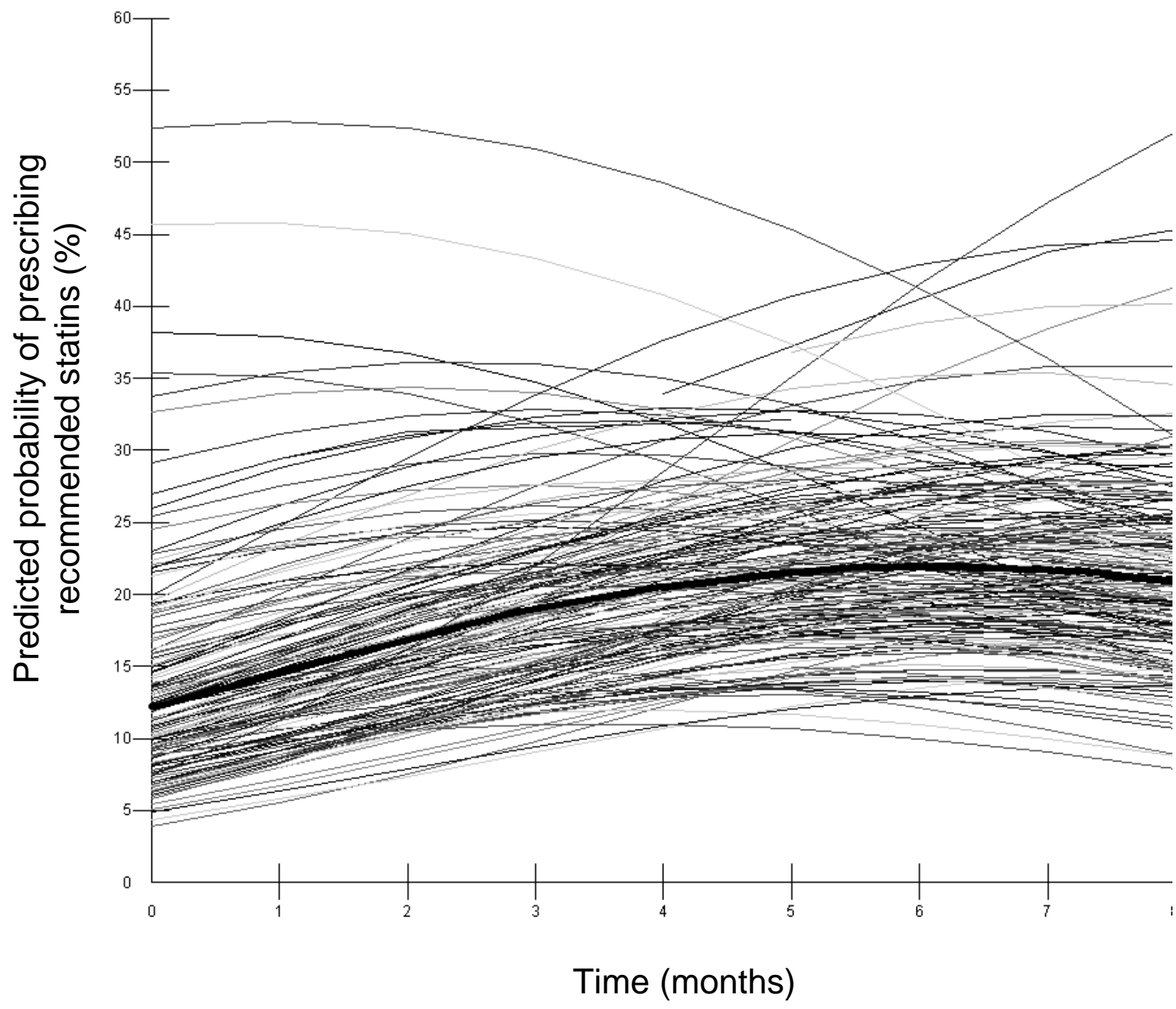

Figure 2 


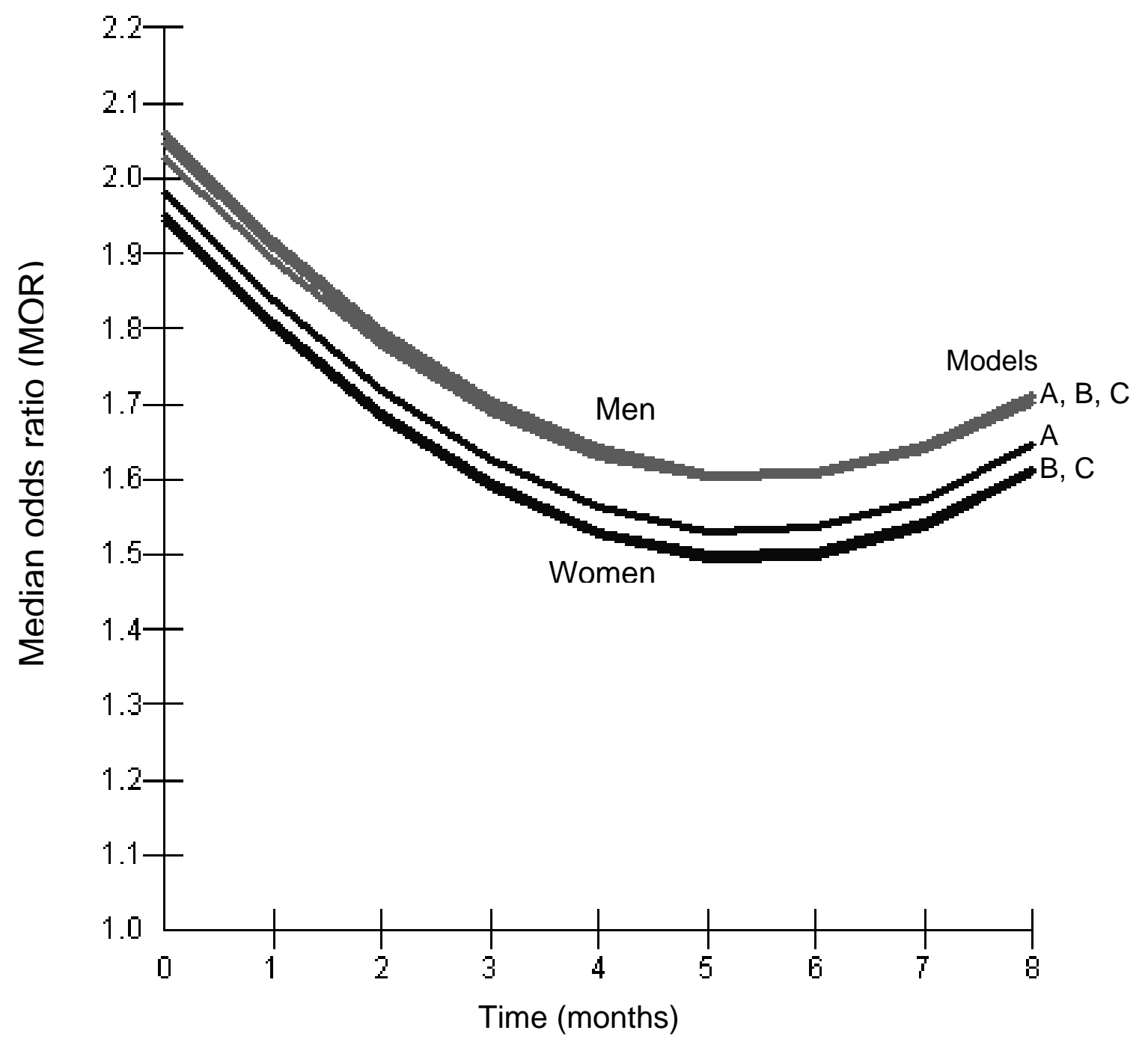

Figure 3 